\title{
Low Rates of Chemotherapy Use for Primary, High-Grade Soft Tissue Sarcoma: A National Cancer Database Analysis
}

\author{
Danielle S. Graham, MD, MBA'; Mykola Onyshchenko, MD²; Mark A. Eckardt, MD 1,3,4; Benjamin J. DiPardo, MD ${ }^{1,4}$; \\ Sriram Venigalla, MD'; Scott D. Nelson, MD; ; Bartosz Chmielowski, MD7,8; Arun S. Singh, MD7,8; \\ Jacob E. Shabason, MD, MTR ${ }^{5,9}$; Fritz C. Eilber, MD ${ }^{1,8}$; and Anusha Kalbasi, MD ${ }^{8,10}$
}

\begin{abstract}
Background: There is conflicting evidence regarding the role of chemotherapy for high-grade soft tissue sarcoma (STS) in adults. We sought to characterize patterns of chemotherapy use, including multiagent and neoadjuvant chemotherapy, in the United States. Patients and Methods: Using the National Cancer Database, we identified 19,969 adult patients who underwent surgical resection for primary high-grade STS from 2004 to 2016. Using logistic regression, we examined factors associated with overall, multiagent, and neoadjuvant chemotherapy use. Results: Chemotherapy was administered to $22 \%(n=4,377)$ of the study population. Among patients treated using chemotherapy, $85 \%$ received multiagent treatment and $47 \%$ received neoadjuvant treatment. On multivariate analysis, factors associated with chemotherapy use included tumor size, depth, histology, and primary site; receipt of radiation treatment; younger age; higher patient income; and academic treatment facility. Factors associated with multiagent chemotherapy use included tumor histology, tumor primary site, and younger age. Factors associated with neoadjuvant chemotherapy use included tumor size, depth, margin status, and primary site; receipt of radiation treatment; higher patient income; academic treatment facility type; and distance to treatment facility. Treatment at a high-volume facility was the only factor associated with overall, multiagent, and neoadjuvant chemotherapy use. No significant temporal trend was seen in overall, multiagent, or neoadjuvant chemotherapy use. Conclusions: Overall chemotherapy use was low (22\%). The variability in chemotherapy use was driven by clinical, patient, demographic, and facility factors. Among patients treated with chemotherapy, the use of multiagent chemotherapy was high (85\%), and nearly half received neoadjuvant therapy. There was a discrepancy in the use of chemotherapy-including neoadjuvant and multiagent chemotherapy-between high- and low-volume treatment centers.
\end{abstract}

J Natl Compr Canc Netw 2020;18(8):1055-1065 doi: $10.6004 /$ jnccn.2020.7553

${ }^{1}$ Division of Surgical Oncology, Department of Surgery, University of California, Los Angeles, Los Angeles, California; ${ }^{2}$ Division of Hematology-Oncology, Department of Internal Medicine, Harbor-UCLA Medical Center, Torrance, California; ${ }^{3}$ Department of Surgery, Yale School of Medicine, New Haven, Connecticut; ${ }^{4}$ Department of Surgery, Greater Los Angeles Veterans Health Administration, Los Angeles, California; ${ }^{5}$ Department of Radiation Oncology, Perelman School of Medicine, University of Pennsylvania, Philadelphia,

Pennsylvania; ${ }^{6}$ Department of Pathology, ${ }^{7}$ Division of Hematology-Oncology, Department of Internal Medicine, and ${ }^{8} \mathrm{~J}$ onsson Comprehensive Cancer Center, University of California, Los Angeles, Los Angeles, California; ${ }^{9}$ Abramson Family Cancer Research Institute, Perelman School of Medicine, University of Pennsylvania, Philadelphia, Pennsylvania; and ${ }^{10}$ Department of Radiation Oncology, University of California, Los Angeles, Los Angeles, California.

\section{Background}

Patients with localized soft tissue sarcoma (STS) are managed with surgery with or without radiation. ${ }^{1-3}$ Despite aggressive local therapy, up to $50 \%$ of patients with high-risk ( $\geq 5 \mathrm{~cm}$, high-grade) primary STS develop metastases, highlighting the critical need for effective systemic therapies. ${ }^{4-11}$ Meta-analyses and prospective clinical trials studying the use of systemic therapies have been limited by the rare and heterogeneous nature of this disease, and provide conflicting evidence regarding the role, number of agents, and timing of chemotherapy for the management of high-risk primary STS in adults. ${ }^{12-26}$

Most recently, a randomized controlled trial (EORTCSTBSG 62931) comparing treatment with doxorubicin and ifosfamide versus observation showed improved diseasefree survival with chemotherapy but no difference in overall survival (OS) between the 2 groups. ${ }^{13,14}$ However, a subsequent analysis examining low-risk and high-risk patients separately showed improved OS with chemotherapy in patients with high-risk disease. ${ }^{15,16}$ In addition, although individual randomized controlled trials have not consistently shown a benefit associated with multiagent chemotherapy, modern meta-analyses have suggested a survival benefit in patients treated with multiagent regimens. ${ }^{16,19}$ There have been no studies to date directly comparing neoadjuvant versus adjuvant chemotherapy, each of which has advantages and disadvantages. Given these data, the NCCN Clinical Practice Guidelines in Oncology (NCCN Guidelines) for STS and European Sarcoma Networking Group guidelines cite chemotherapy as an option for patients with high-risk disease, although they do not provide more definitive recommendations. ${ }^{27,28}$

Two prior studies using the SEER registry and the National Cancer Database (NCDB), respectively, have examined patterns of chemotherapy use in the treatment of STS in the United States. ${ }^{29-32}$ However, neither study

See JNCCN.org for supplemental online content. 
included facility-level factors, such as volume, nor did they examine the timing of chemotherapy or use of single-agent or multiagent chemotherapy. Only 1 study excluded low-grade tumors, for which chemotherapy is not indicated.

Our goal was to determine the rate of chemotherapy, multiagent chemotherapy, and neoadjuvant chemotherapy use in the setting of equivocal evidence for the treatment of adult patients with primary high-grade STS. Furthermore, we sought to characterize the factors associated with the use of each of these treatment regimens at Commission on Cancer (CoC)-accredited facilities in the United States using the NCDB.

\section{Patients and Methods}

\section{Data Source and Cohort Definition}

In this analysis, we used data from the NCDB from 2004 through 2016. The NCDB is a joint project of the CoC of the American College of Surgeons and the American Cancer Society that includes data from $>1,500$ CoCaccredited facilities in the United States, and represents $>70 \%$ of new cancer cases in the United States. ${ }^{32}$

Among patients included in the NCDB, we identified those with STS using ICD-O-3. ${ }^{33}$ We included patients with undifferentiated pleomorphic sarcoma (UPS), highgrade myxoid liposarcoma, synovial sarcoma, malignant peripheral nerve sheath tumor, leiomyosarcoma, liposarcoma, angiosarcoma, fibrosarcoma, fibromyxosarcoma, epithelioid sarcoma, and other undifferentiated or unclassified sarcoma. Exclusion criteria included age $<18$ years, a diagnosis of high-grade dysplasia, unknown or low-grade disease, and the presence of positive nodes or distant metastases. Furthermore, we excluded patients with sarcoma of the head and neck (because there is a unique set of anatomic, prognostic, surgical, and therapeutic considerations for these tumors) and patients who received palliative treatment, were treated with radiation doses that were unknown or outside the range of 40 to $75 \mathrm{~Gy}$ (because these doses suggest that these patients may have had nonlocalized disease), and who had delays $>9$ months from diagnosis to start of any treatment. Finally, patients were excluded who did not undergo surgery or whose surgery status was unknown, those whose physicians recommended chemotherapy but who did not receive it due to extensive comorbidities or premature death, those who did not have any histologic confirmation of malignancy, and those who did not have chemotherapy data available, resulting in 19,969 patients in the final cohort.

For the chemotherapy use analysis, all 19,969 patients were included, of whom 4,377 (22\%) received chemotherapy. The number of chemotherapy agents used was available for 4,109 patients $(94 \%)$, and all of these patients were included in the subgroup analysis of single-agent versus multiagent chemotherapy use. Data regarding the timing of chemotherapy were collected starting in 2006 and were available for 3,699 patients $(85 \%)$, all of whom were included in the subgroup analysis of neoadjuvant versus adjuvant chemotherapy use (Figure 1). Patients with retroperitoneal sarcomawhich is governed by a unique set of anatomic, prognostic, and therapeutic considerations-are listed in a separate NCDB database and thus were not included in this analysis. The data used in the study were derived from a deidentified NCDB file. The American College of Surgeons and CoC have not verified and are not responsible for the analytic or statistical methodology used or for the conclusions drawn from these data by the investigators.

\section{Analytic Variables}

The primary outcome was use of chemotherapy, and we were primarily interested in the demographic, clinical, patient, treatment, and facility factors associated with its use. Secondary outcomes included the use of multiagent versus single-agent chemotherapy and the use of neoadjuvant versus adjuvant chemotherapy.

Annual sarcoma surgical volume was analyzed in the initial NCDB population $(n=106,822)$, before any exclusions, to determine high-volume versus low-volume facilities. The cutoff was the 99th percentile annual surgical case volume (supplemental eFigure 1, available with this article at JNCCN.org), which has been used in prior studies. ${ }^{34,35}$ Distance from patient home to treatment facility was analyzed in the final study population, initially using 10-mile increments (supplemental eFigure 2). Final "distance to treatment facility" groups were based on relatively equal group size and presumed practical relevance.

In addition, we were interested in temporal trends of chemotherapy use over time and in describing time from diagnosis to treatment and duration of treatment.

\section{Statistical Analysis}

We performed univariate and multivariate logistic regression analyses to determine factors associated with chemotherapy use. Any factors that were statistically significant in univariate analysis or that are standard covariates in the literature, such as sex and age, were included in the multivariate logistic regression. The category within each covariate with the most patients was defined as the reference category. To evaluate temporal trends of chemotherapy use, we included date of diagnosis in the multivariate regression model (as both a categorical and a continuous variable) and compared chemotherapy rates in each year (using chi-square test). Bonferroni correction was used to account for multiple hypothesis testing, and statistically significant values are noted in the tables. Results are shown as odds ratios with 95\% CIs. 


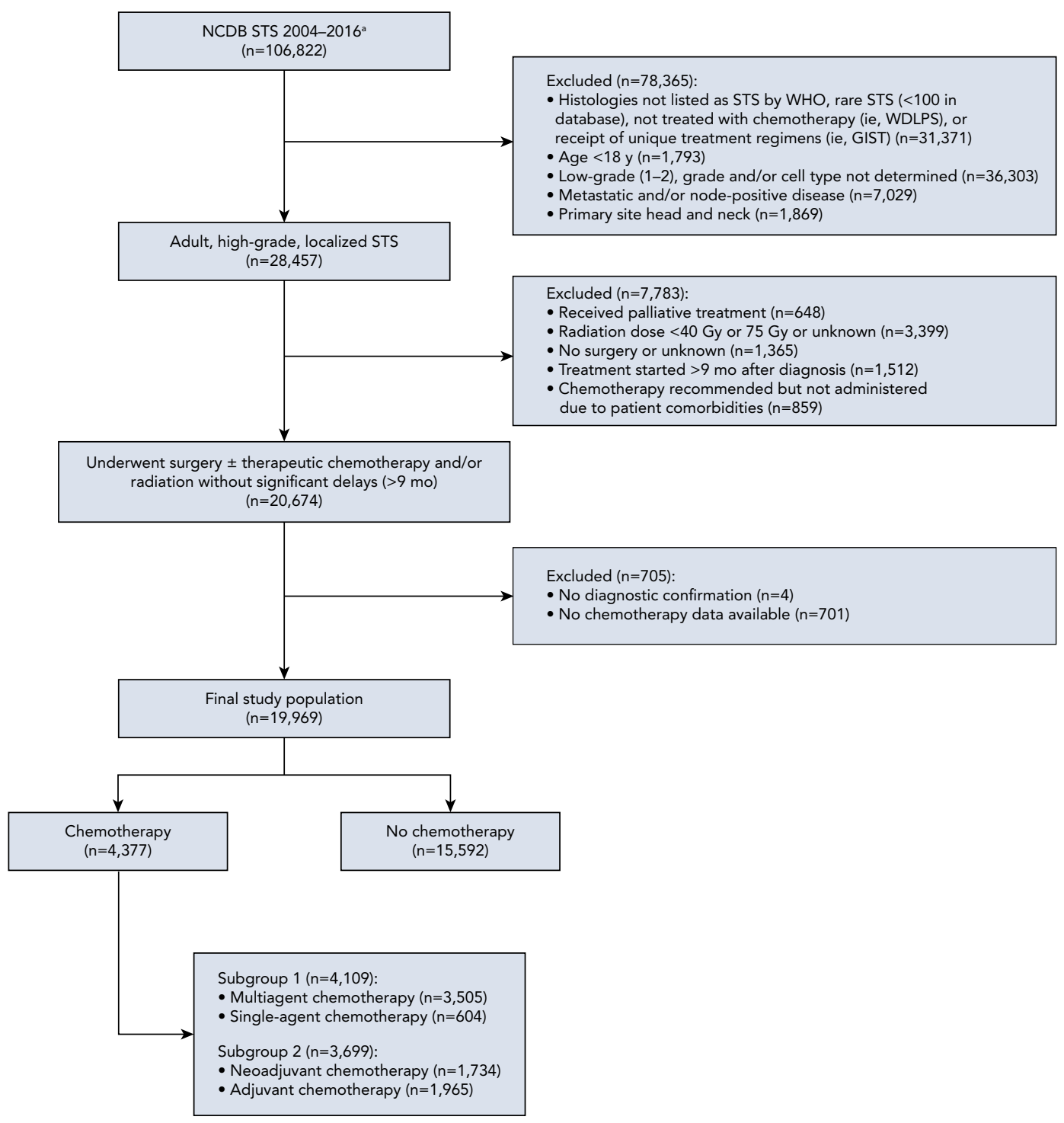

Figure 1. CONSORT diagram showing definition of study cohort from NCDB STS database.

Abbreviations: GIST, gastrointestinal stromal tumor; NCDB, National Cancer Database; STS, soft tissue sarcoma, WDLPS, well-differentiated liposarcoma.

aThis dataset and subsequent analyses do not include patients with retroperitoneal sarcoma; due to unique anatomic, prognostic, and therapeutic considerations, retroperitoneal sarcoma cases are included in a separate NCDB dataset.

To determine factors associated with multiagent and neoadjuvant chemotherapy use, the analysis was repeated on the relevant subgroups. We included all factors that were used in the initial chemotherapy use logistic regression in each of these subgroup analyses. Statistical analysis was performed using STATA, version 15.1 (StataCorp LLP).

\section{Results}

Characteristics of Study Cohort

Overall characteristics of the study cohort are summarized in Table 1 . Most patients were white $(80 \%)$, carried commercial insurance $(45 \%)$ or Medicare $(44 \%)$, were treated at low-volume facilities $(76 \%)$, and lived $<100$ miles from the treatment facility $(88 \%)$. The most common histology was UPS (30\%) and the most common primary site was extremity (62\%). Compared with the primary study cohort (ie, chemotherapy vs no chemotherapy), patients in the subgroup analyses (ie, single-agent vs multiagent chemotherapy or neoadjuvant vs adjuvant chemotherapy) were more likely to be younger, carry commercial insurance, be treated at high-volume facilities, and have larger-size and/or deep tumors. Results are summarized in supplemental eTable 1. 


\section{Table 1. Patient Characteristics}

\section{Characteristic}

n

$\%$

Sex

\begin{tabular}{lrr} 
Male & 10,620 & 53.2 \\
\hline Female & 9,349 & 46.8
\end{tabular}

Age, y

\begin{tabular}{lll}
\hline $18-49$ & 4,429 & 22.2 \\
\hline $50-69$ & 8,281 & 41.5 \\
\hline$\geq 70$ & 7,259 & 36.3
\end{tabular}

Race/Ethnicity

\begin{tabular}{lrr}
\hline White & 16,061 & 80.4 \\
\hline Black & 1,835 & 9.2 \\
\hline Hispanic & 1,173 & 5.9 \\
\hline Other/Unknown & 900 & 4.5
\end{tabular}

Insurance status

\begin{tabular}{lll}
\hline Commercial & 8,912 & 44.6
\end{tabular}

Medicare $\quad 8,686 \quad 43.5$

Medicaid $1,104 \quad 5.5$

Uninsured $\quad 628$

$\begin{array}{lll}\text { Other government/unknown } & 639 & 3.2\end{array}$

Annual income, USD

\begin{tabular}{lrr}
\hline$\geq \$ 63,333$ & 7,392 & 37.0 \\
\hline$\$ 50,354-\$ 63,332$ & 4,691 & 23.5 \\
$\$ 40,227-\$ 50,353$ & 4,311 & 21.6 \\
\hline$<\$ 40,277$ & 3,241 & 16.2 \\
\hline Unknown & 334 & 1.7
\end{tabular}

County type

\begin{tabular}{lrc}
\hline Metropolitan & 16,322 & 81.7 \\
\hline Urban & 2,793 & 14.0 \\
\hline Rural & 336 & 1.7 \\
\hline Unknown & 518 & 2.6 \\
\begin{tabular}{l} 
Facility location \\
\hline South
\end{tabular} & 6,151 & 30.8 \\
\hline East & 3,829 & 19.2 \\
\hline Central & 4,728 & 23.7 \\
\hline West & 3,120 & 15.6 \\
\hline Unknown & 2,141 & 10.7 \\
\hline Facility type & & \\
\hline Nonacademic & 8,065 & 40.4 \\
\hline Academic & 9,763 & 48.9 \\
\hline Unknown & 2,141 & 10.7 \\
\hline Facility volume & & \\
\hline Low & 15,194 & 76.1 \\
\hline High & 4,775 & 23.9 \\
\hline Distance to facility, miles & & \\
\hline $0-9$ & 7,632 & 38.2 \\
\hline 10-29 & 5,785 & 29.0 \\
\hline 30-100 & 4,207 & 21.1 \\
\hline$>100$ & 2,262 & 11.3 \\
\hline Unknown & 83 & 0.4 \\
\hline
\end{tabular}

(continued)

\section{Table 1. Patient Characteristics (cont.)}

\section{Characteristic}

n

$\%$

Year

\begin{tabular}{lll}
\hline $2004-2008$ & 7,287 & 36.5 \\
\hline $2009-2012$ & 5,954 & 29.8 \\
\hline $2013-2016$ & 6,728 & 33.7
\end{tabular}

Charlson-Deyo comorbidity score

\begin{tabular}{lrr}
\hline 0 & 15,865 & 79.5 \\
\hline 1 & 3,144 & 15.7 \\
\hline$\geq 2$ & 960 & 4.8
\end{tabular}

Histology

\begin{tabular}{lll}
\hline UPS & 6,009 & 30.1
\end{tabular}

High-grade myxoid liposarcoma $\quad 581$

Synovial sarcoma $\quad 1,026$

$\begin{array}{lll}\text { MPNST } & 753 & 3.8\end{array}$

\begin{tabular}{lll}
\hline Leiomyosarcoma & 3,040 & 15.2
\end{tabular}

\begin{tabular}{lrr}
\hline Liposarcoma & 2,067 & 10.4
\end{tabular}

\begin{tabular}{lll}
\hline Angiosarcoma & 723 & 3.6
\end{tabular}

Fibrosarcoma $\quad 313 \quad 1.6$

\begin{tabular}{lll}
\hline Fibromyxosarcoma & 1,595 & 8.0
\end{tabular}

Epithelioid sarcoma $\quad 260 \quad 1.3$

$\begin{array}{lll}\text { Other undifferentiated/ } & 3,602 & 18.0\end{array}$

unclassified sarcoma

Primary site

\begin{tabular}{lrr}
\hline Extremity & 12,355 & 61.9 \\
\hline Heart & 153 & 0.8 \\
\hline Trunk & 1,142 & 5.7 \\
\hline Thorax & 1,999 & 10.0 \\
\hline Abdomen/Pelvis & 3,727 & 18.6 \\
\hline Other & 593 & 3.0
\end{tabular}

Tumor size, $\mathrm{cm}$

\begin{tabular}{lll}
\hline$\leq 5$ & 5,371 & 26.9 \\
\hline $5.1-10$ & 6,208 & 31.1 \\
\hline $10.1-15$ & 3,106 & 15.5 \\
\hline$>15$ & 2,530 & 12.7 \\
\hline Unknown & 2,754 & 13.8
\end{tabular}

Tumor depth

\begin{tabular}{lll}
\hline Deep & 9,027 & 45.2 \\
\hline Superficial & 4,908 & 24.6 \\
\hline Unknown & 6,034 & 30.2
\end{tabular}

Surgical margins

\begin{tabular}{lrc}
\hline Negative & 15,169 & 76.0 \\
\hline Positive & 3,525 & 17.6 \\
\hline Unknown & 1,275 & 6.4 \\
Radiation therapy & & \\
\hline Yes & 10,949 & 54.8 \\
\hline No & 9,020 & 45.2
\end{tabular}

Abbreviations: MPNST, malignant peripheral nerve sheath tumor; UPS, undifferentiated pleomorphic sarcoma. 


\section{Table 2. Factors Associated With Chemotherapy Use}

\begin{tabular}{|c|c|c|c|c|c|}
\hline Characteristic & $\begin{array}{c}\text { Chemotherapy } \\
\text { n (\%) }\end{array}$ & $\begin{array}{c}\text { Unadjusted OR } \\
(95 \% \mathrm{CI})\end{array}$ & $P$ Value & $\begin{array}{c}\text { Adjusted OR } \\
(95 \% \mathrm{Cl})\end{array}$ & $P$ Value \\
\hline \multicolumn{6}{|l|}{ Age, y } \\
\hline $50-69$ & $2,129(25.7)$ & Ref & & Ref & \\
\hline$\geq 70$ & $533(7.3)$ & $0.23(0.21-0.25)$ & $<.001$ & $0.28(0.25-0.32)$ & $<.001$ \\
\hline Medicare & $960(11.1)$ & $0.28(0.26-0.30)$ & $<.001$ & $0.68(0.61-0.76)$ & $<.001$ \\
\hline Medicaid & $347(31.4)$ & $1.03(0.90-1.18)$ & .686 & $0.85(0.73-0.99)$ & .033 \\
\hline Uninsured & $170(27.1)$ & $0.83(0.69-1.00)$ & .048 & $0.69(0.57-0.84)$ & $<.001$ \\
\hline Other government/unknown & $152(23.8)$ & $0.70(0.58-0.84)$ & $<.001$ & $0.82(0.67-1.00)$ & .054 \\
\hline$\$ 40,227-\$ 50,353$ & $930(21.6)$ & $0.92(0.84-1.01)$ & .078 & $0.92(0.83-1.02)$ & .131 \\
\hline$<\$ 40,277$ & $630(19.4)$ & $0.81(0.73-0.90)$ & $<.001$ & $0.78(0.69-0.88)$ & $<.001$ \\
\hline Unknown & $59(17.7)$ & $0.72(0.54-0.96)$ & .024 & $0.62(0.43-0.90)$ & .011 \\
\hline \multicolumn{6}{|l|}{ Facility location } \\
\hline South & $1,114(18.1)$ & Ref & & Ref & \\
\hline East & $648(16.9)$ & $0.92(0.83-1.02)$ & .130 & $0.85(0.75-0.96)$ & .008 \\
\hline Central & $1,063(22.5)$ & $1.31(1.19-1.44)$ & $<.001$ & $1.29(1.16-1.43)$ & $<.001$ \\
\hline West & $665(21.3)$ & $1.22(1.10-1.36)$ & $<.001$ & $1.21(1.07-1.37)$ & .002 \\
\hline Unknown & $887(41.4)$ & $3.20(2.87-3.56)$ & $<.001$ & $1.45(1.24-1.69)$ & $<.001$ \\
\hline High & $1,296(27.1)$ & $1.46(1.36-1.58)$ & $<.001$ & $1.32(1.19-1.45)$ & $<.001$ \\
\hline \multicolumn{6}{|l|}{ Histology } \\
\hline UPS & $1,121(18.7)$ & Ref & & Ref & \\
\hline High-grade myxoid liposarcoma & $182(31.3)$ & $1.99(1.65-2.40)$ & $<.001$ & $0.94(0.77-1.15)$ & .549 \\
\hline Synovial sarcoma & $511(49.8)$ & $4.33(3.77-4.97)$ & $<.001$ & $2.35(2.01-2.76)$ & $<.001$ \\
\hline MPNST & $207(27.5)$ & $1.65(1.39-1.96)$ & $<.001$ & $0.79(0.65-0.96)$ & .017 \\
\hline Leiomyosarcoma & $609(20.0)$ & $1.09(0.98-1.22)$ & .116 & $0.99(0.87-1.12)$ & .825 \\
\hline Liposarcoma & $371(17.9)$ & $0.95(0.84-1.09)$ & .475 & $0.68(0.59-0.79)$ & $<.001$ \\
\hline Angiosarcoma & $223(30.8)$ & $1.94(1.64-2.31)$ & $<.001$ & $2.59(2.12-3.18)$ & $<.001$ \\
\hline Fibrosarcoma & $48(15.3)$ & $0.79(0.58-1.08)$ & .141 & $0.71(0.51-0.99)$ & .047 \\
\hline Fibromyxosarcoma & $222(13.9)$ & $0.71(0.60-0.82)$ & $<.001$ & $0.72(0.61-0.86)$ & $<.001$ \\
\hline Epithelioid sarcoma & $59(22.7)$ & $1.28(0.95-1.72)$ & .104 & $0.97(0.70-1.34)$ & .846 \\
\hline $\begin{array}{l}\text { Other undifferentiated/ } \\
\text { unclassified sarcoma }\end{array}$ & $824(22.9)$ & $1.29(1.17-1.43)$ & $<.001$ & $1.18(1.05-1.32)$ & .004 \\
\hline
\end{tabular}




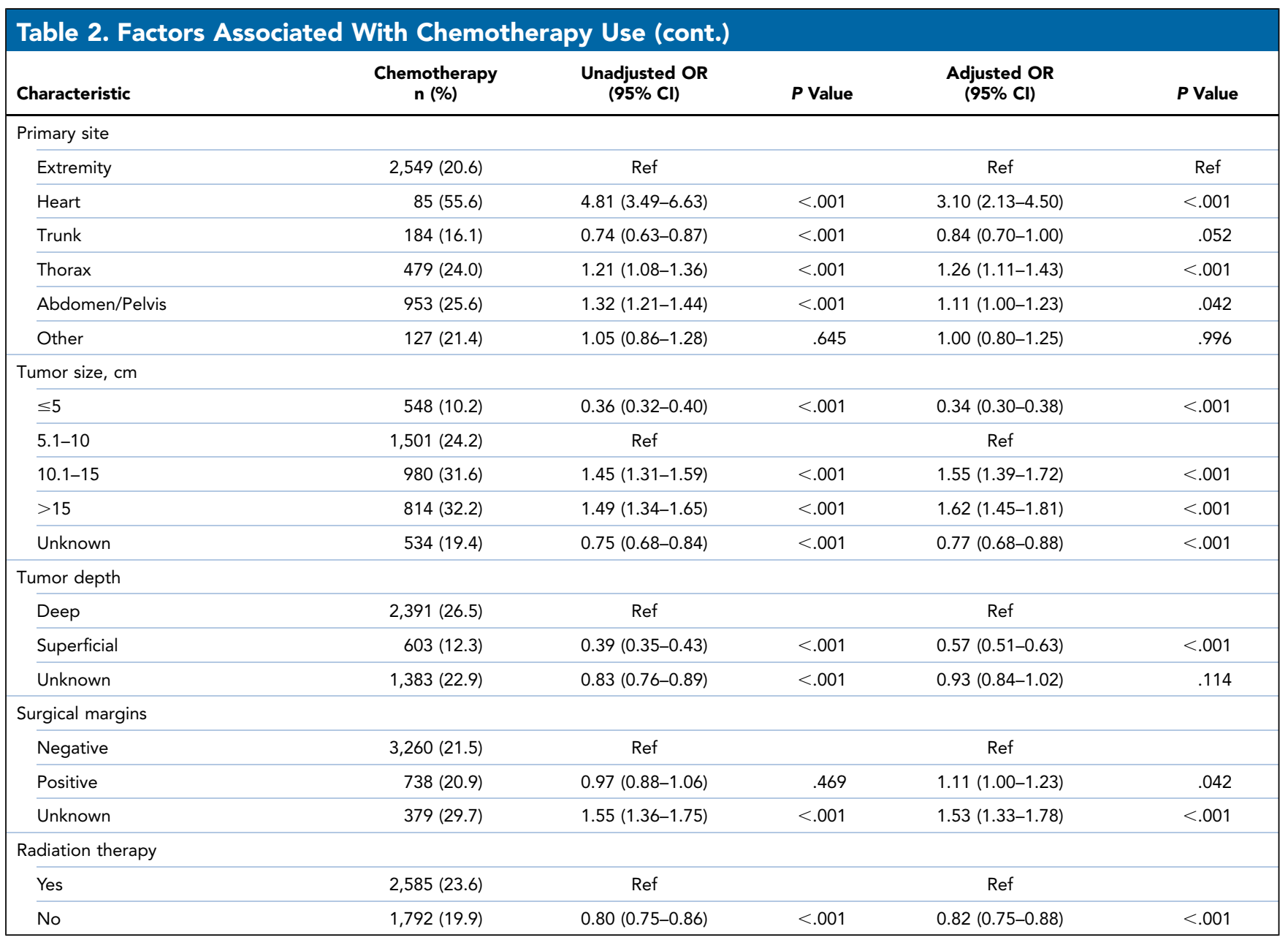

Abbreviations: MPNST, malignant peripheral nerve sheath tumor; OR, odds ratio; UPS, undifferentiated pleomorphic sarcoma.

\section{Factors Associated With Chemotherapy Use}

Chemotherapy was administered to $22 \%(n=4,377)$ of the study population. On multivariate analysis, factors associated with chemotherapy use included younger age, academic facility type, high-volume facility, larger tumor size, greater tumor depth, positive surgical margins, and receipt of RT (Table 2). Histologies associated with the highest rates of chemotherapy use were synovial sarcoma (50\%) and angiosarcoma (31\%), whereas fibromyxosarcoma (14\%) and liposarcoma (18\%) were associated with the lowest rates of chemotherapy use. The primary tumor site associated with the highest rate of chemotherapy use was the heart (56\%) and the lowest was the trunk (16\%).

\section{Factors Associated With Multiagent}

Chemotherapy Use

Of the patients included in the multiagent versus singleagent chemotherapy analysis, $85 \%(n=3,505)$ received multiagent chemotherapy. On multivariate analysis, factors associated with multiagent chemotherapy use were younger age, tumor histology, primary site, and treatment at a high-volume facility (Table 3). By histology, multiagent chemotherapy use was lowest in angiosarcoma (49\%) and highest in leiomyosarcoma (90\%) and synovial sarcoma (90\%).

\section{Factors Associated With Neoadjuvant Chemotherapy Use}

Of the patients included in the neoadjuvant versus adjuvant chemotherapy analysis, $47 \%(n=1,734)$ were treated using neoadjuvant chemotherapy. On multivariate analysis, factors associated with neoadjuvant chemotherapy use included higher income, academic facility type, high-volume facility, greater distance from treatment facility, larger tumor size, and receipt of RT (Table 4). Patients with UPS (53\%) were more likely to undergo treatment using neoadjuvant chemotherapy, whereas those with angiosarcoma (27\%) were the least likely. Patients with tumors in the extremities (57\%) were the most likely to undergo neoadjuvant chemotherapy, whereas those with tumors in the heart (8\%) were the least 


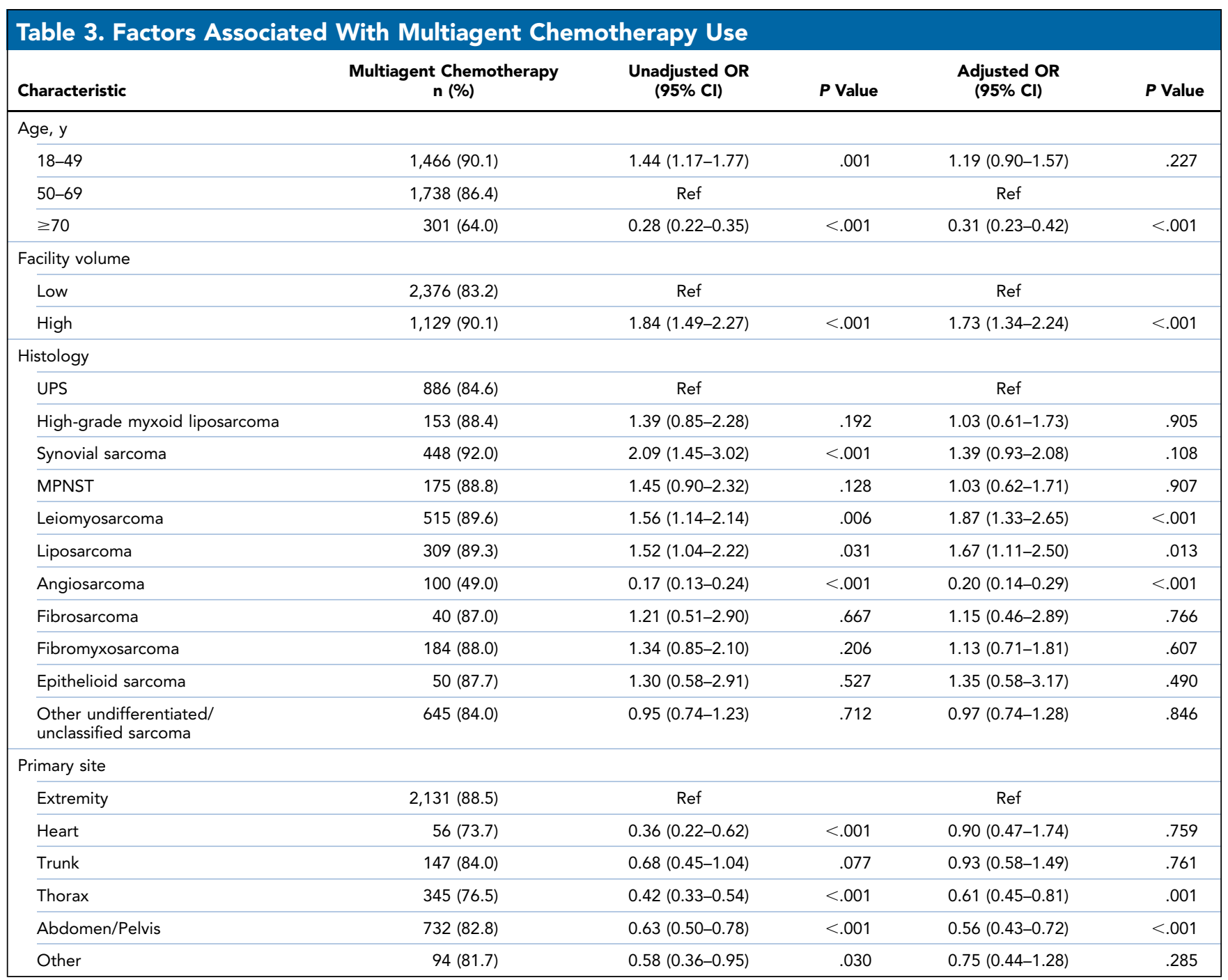

Abbreviations: MPNST, malignant peripheral nerve sheath tumor; OR, odds ratio; UPS, undifferentiated pleomorphic sarcoma.

likely. Patients with positive surgical margins were more likely to receive adjuvant than neoadjuvant chemotherapy.

Temporal Trends of Chemotherapy, Neoadjuvant Chemotherapy, and Multiagent Chemotherapy Use Trends of chemotherapy use, timing, and multiagent therapy are shown in supplemental eFigure 3 and eTable 2. No meaningful change in the use of chemotherapy over time was noted.

\section{Discussion}

The results of our analysis show the patterns of chemotherapy use, including multiagent and neoadjuvant chemotherapy, for patients with primary high-grade STS treated with primary surgery across CoC-accredited facilities in the United States. The overall rate of chemotherapy use was $22 \%$; in young (aged $<50$ years), healthy (Charlson-Deyo comorbidity condition [CDCC] score of
0) patients with high-risk disease (high-grade, $>10 \mathrm{~cm}$ ), use rates reached $45 \%$.

Even in the setting of equivocal data, these rates may be lower than anticipated. However, our findings regarding overall chemotherapy use are consistent with prior literature. ${ }^{11}$ Factors associated with higher rates of chemotherapy use included larger tumor size and deep tumors, consistent with earlier findings that these patients preferentially benefit from chemotherapy. ${ }^{11,15,36-38}$ Facility-level variables were also associated with increased chemotherapy use, including high-volume and academic type. The primary tumor site that was associated with the highest rate of chemotherapy use was the heart. This is consistent with prior literature, which has shown both high rates of chemotherapy use and improved survival associated with chemotherapy for this rare tumor type. $^{39-42}$ 


\section{Table 4. Factors Associated With Neoadjuvant Chemotherapy Use}

\begin{tabular}{|c|c|c|c|c|c|}
\hline Characteristic & $\begin{array}{c}\text { Neoadjuvant Chemotherapy } \\
\text { n (\%) }\end{array}$ & $\begin{array}{l}\text { Unadjusted OR } \\
(95 \% \mathrm{Cl})\end{array}$ & $P$ Value & $\begin{array}{l}\text { Adjusted OR } \\
(95 \% \mathrm{Cl})\end{array}$ & $P$ Value \\
\hline \multicolumn{6}{|l|}{ Annual income, USD } \\
\hline$\geq \$ 63,333$ & $681(46.9)$ & Ref & & Ref & \\
\hline$\$ 50,354-\$ 63,332$ & $424(47.7)$ & $1.03(0.87-1.22)$ & .702 & $0.94(0.78-1.13)$ & .505 \\
\hline$\$ 40,227-\$ 50,353$ & $394(50.3)$ & $1.14(0.96-1.36)$ & .134 & $0.97(0.80-1.19)$ & .801 \\
\hline$<\$ 40,277$ & 209 (39.6) & $0.74(0.60-0.91)$ & .004 & $0.65(0.51-0.83)$ & $<.001$ \\
\hline Unknown & $26(54.2)$ & $1.34(0.75-2.38)$ & .325 & $0.86(0.43-1.71)$ & .661 \\
\hline \multicolumn{6}{|l|}{ Facility type } \\
\hline Nonacademic & 402 (35.9) & Ref & & Ref & \\
\hline Academic & $998(54.4)$ & $2.13(1.83-2.48)$ & $<.001$ & $1.42(1.17-1.72)$ & $<.001$ \\
\hline Unknown & $334(44.8)$ & $1.45(1.20-1.75)$ & $<.001$ & - & - \\
\hline \multicolumn{6}{|l|}{ Facility volume } \\
\hline Low & $1,086(41.4)$ & Ref & & Ref & \\
\hline High & $648(60.4)$ & $2.16(1.87-2.50)$ & $<.001$ & $1.50(1.25-1.79)$ & $<.001$ \\
\hline \multicolumn{6}{|c|}{ Distance to treatment, miles } \\
\hline $0-9$ & $474(37.7)$ & Ref & & Ref & \\
\hline $10-29$ & $527(46.2)$ & $1.42(1.20-1.67)$ & $<.001$ & $1.26(1.05-1.51)$ & .013 \\
\hline $30-100$ & $427(51.8)$ & $1.77(1.48-2.11)$ & $<.001$ & $1.50(1.22-1.84)$ & $<.001$ \\
\hline$>100$ & $300(64.1)$ & $2.95(2.36-3.67)$ & $<.001$ & $2.33(1.79-3.03)$ & $<.001$ \\
\hline Unknown & $6(66.7)$ & $3.30(0.82-13.26)$ & .092 & $2.87(0.58-14.12)$ & .195 \\
\hline \multicolumn{6}{|l|}{ Year } \\
\hline 2004-2008 & $444(44.0)$ & Ref & & Ref & \\
\hline 2009-2012 & $616(46.7)$ & $1.12(0.95-1.32)$ & .188 & $1.28(1.06-1.55)$ & .011 \\
\hline $2013-2016$ & $674(49.2)$ & $1.23(1.05-1.45)$ & .011 & $1.48(1.20-1.82)$ & $<.001$ \\
\hline \multicolumn{6}{|l|}{ Primary site } \\
\hline Extremity & $1,211(56.5)$ & Ref & & Ref & \\
\hline Heart & - & - & - & $0.18(0.07-0.44)$ & $<.001$ \\
\hline Trunk & $61(38.1)$ & $0.48(0.34-0.66)$ & $<.001$ & $0.56(0.39-0.80)$ & .002 \\
\hline Thorax & $158(38.2)$ & $0.48(0.38-0.59)$ & $<.001$ & $0.66(0.51-0.84)$ & .001 \\
\hline Abdomen/Pelvis & $269(33.7)$ & $0.39(0.33-0.46)$ & $<.001$ & $0.57(0.46-0.69)$ & $<.001$ \\
\hline Other & - & - & - & $0.44(0.27-0.70)$ & .001 \\
\hline \multicolumn{6}{|l|}{ Tumor size, cm } \\
\hline$\leq 5$ & $145(32.8)$ & $0.63(0.50-0.79)$ & $<.001$ & $0.73(0.57-0.94)$ & .014 \\
\hline $5.1-10$ & $549(43.6)$ & Ref & & Ref & \\
\hline $10.1-15$ & $455(55.7)$ & $1.63(1.36-1.94)$ & $<.001$ & $1.62(1.33-1.97)$ & $<.001$ \\
\hline$>15$ & $374(54.2)$ & $1.53(1.27-1.85)$ & $<.001$ & $1.68(1.36-2.08)$ & $<.001$ \\
\hline Unknown & $211(43.1)$ & $0.98(0.79-1.21)$ & .847 & $1.11(0.87-1.42)$ & .389 \\
\hline \multicolumn{6}{|l|}{ Tumor depth } \\
\hline Deep & 1,022 (47.9) & Ref & & Ref & \\
\hline Superficial & $228(43.1)$ & $0.82(0.68-1.00)$ & .046 & $0.98(0.79-1.22)$ & .871 \\
\hline Unknown & $484(46.6)$ & $0.95(0.82-1.10)$ & .489 & $1.52(1.26-1.83)$ & $<.001$ \\
\hline \multicolumn{6}{|l|}{ Surgical margins } \\
\hline Negative & $1,469(53.5)$ & Ref & & Ref & \\
\hline Positive & $191(29.9)$ & $0.37(0.31-0.45)$ & $<.001$ & $0.46(0.37-0.56)$ & $<.001$ \\
\hline Unknown & $74(23.7)$ & $0.27(0.21-0.36)$ & $<.001$ & $0.43(0.32-0.58)$ & $<.001$ \\
\hline \multicolumn{6}{|l|}{ Radiation therapy } \\
\hline Yes & $1,224(55.3)$ & Ref & & Ref & \\
\hline No & $510(34.4)$ & $0.42(0.37-0.49)$ & $<.001$ & $0.53(0.45-0.62)$ & $<.001$ \\
\hline
\end{tabular}

Abbreviation: $O R$, odds ratio. 
Among patients receiving chemotherapy, multiagent chemotherapy was commonly used $(85 \%)$. Although there are no definitive guidelines regarding the use of multiagent chemotherapy, available data have shown the benefits of multiagent regimens. ${ }^{16}$ Therefore, this high rate of use noted in our study may be an expected finding. Notably, older age ( $\geq 70$ years) was associated with decreased rates of multiagent chemotherapy use, possibly due to concern related to treatment morbidity, given that patients in this age group had the highest rates of CDCC scores of $\geq 2$ (7.7\% vs $1.5 \%$ in patients aged $18-49$ years and $4.1 \%$ in patients aged $50-69$ years; $P<.001$ ). However, whether the morbidity of multiagent chemotherapy outweighs the benefits in an older age group deserves further study. Furthermore, the lowest rates of multiagent chemotherapy use were in patients with angiosarcoma. A prior phase II study examining patients with metastatic or unresectable angiosarcoma showed a survival benefit with the use of paclitaxel, a singleagent regimen. ${ }^{43}$ The results of that trial may explain the high use of single-agent regimens observed in our study.

The overall rate of neoadjuvant chemotherapy use was $47 \%$, which reflects the equivocal nature of the current data on timing of chemotherapy for primary high-grade STS. Although neoadjuvant chemotherapy provides an opportunity to evaluate treatment response and for downstaging, the availability of surgical pathology in the adjuvant setting may result in more refined patient selection. In our cohort, neoadjuvant chemotherapy use was more frequent in patients with larger tumors, presumably for the potential downstaging impact. $^{44}$

High facility volume was associated with increased chemotherapy use, including both multiagent and neoadjuvant, and was the only variable associated with use rates in all 3 cohorts. Facility volume correlates with increased compliance with oncologic treatment guidelines, ${ }^{45,46}$ and treatment at high-volume facilities has been associated with improved survival in multiple cancer types, including sarcoma. ${ }^{47-50}$

Two prior studies, using data from NCDB and SEER, examined chemotherapy use in patients with sarcoma. ${ }^{29,31}$ Notable differences were that our study examined the factors associated with multiagent and neoadjuvant chemotherapy use in addition to overall chemotherapy use. Finally, facility-level variables, including facility volume, were not included in the prior studies.

This study has limitations. First, our study was limited to CoC-accredited facilities in the United States.
In general, $\mathrm{CoC}$ facilities tend to be larger, are more frequently located in urban areas, have higher surgical volume, and more frequently treat patients with cancer compared with non-CoC-accredited facilities. ${ }^{51,52}$ Second, although the NCDB is fairly comprehensive, it only represents approximately $70 \%$ of new cancer diagnoses annually. ${ }^{32}$ Together, these factors may limit the generalizability of our findings. Third, although this study is retrospective and hypothesis-generating, causal links cannot be established. Fourth, there are no data regarding referral patterns or patient preferences in the NCDB. Therefore, there may be factors associated with care at high-volume centers that were not captured in these data. In addition, there may be variability in how various centers code clinical data, particularly what is considered chemotherapy versus systemic therapy.

\section{Conclusions}

We observed low rates of chemotherapy use in this population of patients with high-risk STS. Among patients receiving chemotherapy, the preference for multiagent chemotherapy and the balanced use of neoadjuvant and adjuvant chemotherapy reflected the nature of the existing clinical data. Treatment at a high-volume facility was the only variable associated with the use of chemotherapy, multiagent chemotherapy, and neoadjuvant chemotherapy, suggesting a preference for these approaches at more experienced treatment centers.

Submitted August 26, 2019; accepted for publication February 19, 2020.

Author contributions: Study design: Graham, Onyshchenko, Kalbasi. Data acquisition, analysis, and interpretation, including statistical analysis: Graham, Kalbasi. Manuscript draft: Graham, Kalbasi. Critical review and edit of final draft: All authors. Project supervision: Eilber, Kalbasi.

Disclosures: Dr. Onyshchenko has disclosed that he is a scientific advisor for Bayer. Dr. Singh has disclosed that he is a scientific advisor for Eli Lilly, Roche, and Blueprints; has received honoraria/consulting fees from Daiichi Sankyo, Deciphera, Eisai, Eli Lilly, Novartis, Expert Perspectives, and OncLive; a consultant for Daiichi Sankyo and Eisai; a member of the board of directors of and shareholder in Certis Oncology Solutions; and receives grant/research support from Eli Lilly, Deciphera, Nanocarrier, and Blueprints. Dr. Eilber has disclosed that he is a scientific advisor for Certis Oncology Solutions. The remaining authors have disclosed that they have not received any financial consideration from any person or organization to support the preparation, analysis, results, or discussion of this article.

Funding: This work was supported by funding from the Department of Radiation Oncology, UCLA Health System (IDOEQJAG3359), the Division of Surgical Oncology, Department of Surgery, UCLA Health System (IDOE6JAG3360), and the Jonsson Comprehensive Cancer Center, UCLA Health System (IDOEOKAG3361).

Correspondence: Anusha Kalbasi, MD, Department of Radiation Oncology, Jonsson Comprehensive Cancer Center, University of California, Los Angeles, 700 Tiverton Avenue, B-262 Factor Building, Los Angeles, CA 90095. Email: anushakalbasi@mednet.ucla.edu; and Fritz C. Eilber, MD, Division of Surgical Oncology, Jonsson Comprehensive Cancer Center, University of California, Los Angeles, 10833 Le Conte Avenue, 54-140 CHS, Los Angeles, CA 90095.

Email: fceilber@mednet.ucla.edu 


\section{References}

1. Ferguson PC, Deheshi BM, Chung $P$, et al. Soft tissue sarcoma presenting with metastatic disease: outcome with primary surgical resection. Cancer 2011;117:372-379.

2. American Cancer Society. Cancer facts \& figures 2020. Atlanta: American Cancer Society; 2020

3. Sarcoma, soft tissue: statistics. Accessed July 24, 2019. Available at: https://www.cancer.net/cancer-types/sarcoma-soft-tissue/statistics

4. Brennan MF, Antonescu CR, Moraco N, et al. Lessons learned from the study of 10,000 patients with soft tissue sarcoma. Ann Surg 2014;260: 416-421; discussion 421-422.

5. Trovik CS, Bauer HC, Alvegård TA, et al. Surgical margins, local recurrence and metastasis in soft tissue sarcomas: 559 surgically-treated patients from the Scandinavian Sarcoma Group Register. Eur J Cancer 2000; 36:710-716

6. Rööser B, Gustafson P, Rydholm A. Is there no influence of local control on the rate of metastases in high-grade soft tissue sarcoma? Cancer 1990;65: 1727-1729.

7. Gustafson P. Soft tissue sarcoma. Epidemiology and prognosis in 508 patients. Acta Orthop Scand Suppl 1994;259:1-31.

8. Gustafson P, Rööser B, Rydholm A. Is local recurrence of minor importance for metastases in soft tissue sarcoma? Cancer 1991;67:2083-2086.

9. Alamanda VK, Crosby SN, Archer KR, et al. Predictors and clinical significance of local recurrence in extremity soft tissue sarcoma. Acta Oncol 2013;52:793-802.

10. Weitz J, Antonescu CR, Brennan MF. Localized extremity soft tissue sarcoma: improved knowledge with unchanged survival over time. J Clin Oncol 2003;21:2719-2725

11. Zaidi MY, Ethun CG, Tran TB, et al. Assessing the role of neoadjuvant chemotherapy in primary high-risk truncal/extremity soft tissue sarcomas: an analysis of the multi-institutional U.S. Sarcoma Collaborative. Ann Surg Oncol 2019;26:3542-3549.

12. Bramwell V, Rouesse J, Steward W, et al. Adjuvant CYVADIC chemotherapy for adult soft tissue sarcoma-reduced local recurrence but no improvement in survival: a study of the European Organization for Research and Treatment of Cancer Soft Tissue and Bone Sarcoma Group. $\mathrm{J}$ Clin Oncol 1994;12:1137-1149.

13. Woll PJ, Reichardt P, Le Cesne A, et al. Adjuvant chemotherapy with doxorubicin, ifosfamide, and lenograstim for resected soft-tissue sarcoma (EORTC 62931): a multicentre randomised controlled trial. Lancet Oncol 2012;13:1045-1054.

14. Le Cesne A, Ouali M, Leahy MG, et al. Doxorubicin-based adjuvant chemotherapy in soft tissue sarcoma: pooled analysis of two STBSGEORTC phase III clinical trials. Ann Oncol 2014;25:2425-2432.

15. Pasquali S, Pizzamiglio S, Touati N, et al. The impact of chemotherapy on survival of patients with extremity and trunk wall soft tissue sarcoma: revisiting the results of the EORTC-STBSG 62931 randomised trial. Eur J Cancer 2019;109:51-60

16. Zer A, Prince RM, Amir E, et al. Multi-agent chemotherapy in advanced soft tissue sarcoma (STS)-a systematic review and meta-analysis. Cancer Treat Rev 2018;63:71-78.

17. Gortzak E, Azzarelli A, Buesa J, et al. A randomised phase II study on neoadjuvant chemotherapy for "high-risk" adult soft-tissue sarcoma. Eur J Cancer 2001;37:1096-1103.

18. Tierney JF, Mosseri V, Stewart LA, et al. Adjuvant chemotherapy for softtissue sarcoma: review and meta-analysis of the published results of randomised clinical trials. Br J Cancer 1995;72:469-475.

19. Pervaiz N, Colterjohn N, Farrokhyar F, et al. A systematic meta-analysis of randomized controlled trials of adjuvant chemotherapy for localized resectable soft-tissue sarcoma. Cancer 2008;113:573-581.

20. Italiano A, Delva F, Mathoulin-Pelissier S, et al. Effect of adjuvant chemotherapy on survival in FNCLCC grade 3 soft tissue sarcomas: a multivariate analysis of the French Sarcoma Group Database. Ann Oncol 2010;21:2436-2441.

21. Frustaci S, Gherlinzoni F, De Paoli A, et al. Adjuvant chemotherapy for adult soft tissue sarcomas of the extremities and girdles: results of the Italian randomized cooperative trial. J Clin Oncol 2001;19:1238-1247.

22. Sarcoma Meta-Analysis Collaboration. Adjuvant chemotherapy for localised resectable soft-tissue sarcoma of adults: meta-analysis of individual data. Lancet 1997;350:1647-1654.

23. Gronchi A, Ferrari S, Quagliuolo V, et al. Histotype-tailored neoadjuvant chemotherapy versus standard chemotherapy in patients with high-risk soft-tissue sarcomas (ISG-STS 1001): an international, open-label, randomised, controlled, phase 3, multicentre trial. Lancet Oncol 2017;18 812-822.

24. Cormier JN, Huang $X$, Xing $Y$, et al. Cohort analysis of patients with localized, high-risk, extremity soft tissue sarcoma treated at two cancer centers: chemotherapy-associated outcomes. J Clin Oncol 2004;22: 4567-4574.

25. Gronchi A, Frustaci S, Mercuri M, et al. Short, full-dose adjuvant chemotherapy in high-risk adult soft tissue sarcomas: a randomized clinica trial from the Italian Sarcoma Group and the Spanish Sarcoma Group. J Clin Oncol 2012;30:850-856.

26. Gronchi A, Stacchiotti S, Verderio P, et al. Short, full-dose adjuvant chemotherapy (CT) in high-risk adult soft tissue sarcomas (STS): long-term follow-up of a randomized clinical trial from the Italian Sarcoma Group and the Spanish Sarcoma Group. Ann Oncol 2016;27:2283-2288.

27. von Mehren M, Randall RL, Benjamin RS et al. NCCN Clinical Practice Guidelines in Oncology: Soft Tissue Sarcoma. Version 2.2018. Accessed July 9, 2019. To view the most recent version, visit NCCN.org

28. ESMO/European Sarcoma Network Working Group. Soft tissue and visceral sarcomas: ESMO Clinical Practice Guidelines for diagnosis, treatment and follow-up [published correction in Ann Oncol 2015; 26(Suppl 5):v174-177]. Ann Oncol 2014;25(Suppl 3):iii102-112.

29. Gadgeel SM, Harlan LC, Zeruto CA, et al. Patterns of care in a populationbased sample of soft tissue sarcoma patients in the United States. Cancer 2009;115:2744-2754

30. National Cancer Institute. Surveillance, Epidemiology, and End Results Program. Accessed July 21, 2019. Available at: https://seer.cancer.gov/

31. Movva S, von Mehren M, Ross EA, et al. Patterns of chemotherapy administration in high-risk soft tissue sarcoma and impact on overall survival. J Natl Compr Canc Netw 2015;13:1366-1374.

32. American College of Surgeons. National Cancer Database. Accessed July 22, 2019. Available at: https://www.facs.org/quality-programs/ cancer/ncdb

33. International Association of Cancer Registries. International Classification of Diseases for Oncology. Accessed February 28, 2020. Available at: http://www.iacr.com.fr/index.php?option =com_content\&view $=$ category\&layout=blog\&id $=100 \&$ ltemid $=577$

34. Venigalla $\mathrm{S}, \mathrm{Nead} \mathrm{KT}$, Sebro R, et al. Association between treatment at high-volume facilities and improved overall survival in soft tissue sarcomas. Int J Radiat Oncol Biol Phys 2018;100:1004-1015.

35. David JM, Ho AS, Luu M, et al. Treatment at high-volume facilities and academic centers is independently associated with improved survival in patients with locally advanced head and neck cancer. Cancer 2017;123: 3933-3942.

36. Pasquali S, Colombo C, Pizzamiglio S, et al. High-risk soft tissue sarcomas treated with perioperative chemotherapy: improving prognostic classification in a randomised clinical trial. Eur J Cancer 2018;93:28-36.

37. Grobmyer SR, Maki RG, Demetri GD, et al. Neo-adjuvant chemotherapy for primary high-grade extremity soft tissue sarcoma. Ann Oncol 2004;15: 1667-1672.

38. Mahmoud O, Tunceroglu A, Chokshi R, et al. Overall survival advantage of chemotherapy and radiotherapy in the perioperative management of large extremity and trunk soft tissue sarcoma; a large database analysis. Radiother Oncol 2017;124:277-284.

39. Bakaeen FG, Jaroszewski DE, Rice DC, et al. Outcomes after surgical resection of cardiac sarcoma in the multimodality treatment era. J Thorac Cardiovasc Surg 2009;137:1454-1460.

40. Burke AP, Cowan D, Virmani R. Primary sarcomas of the heart. Cancer 1992;69:387-395.

41. Hamidi M, Moody JS, Weigel TL, et al. Primary cardiac sarcoma. Ann Thorac Surg 2010;90:176-181.

42. Siontis $\mathrm{BL}$, Zhao L, Leja $\mathrm{M}$, et al. Primary cardiac sarcoma: a rare, aggressive malignancy with a high propensity for brain metastases. Sarcoma 2019:2019:1960593.

43. Penel N, Bui BN, Bay JO, et al. Phase II trial of weekly paclitaxel for unresectable angiosarcoma: the ANGIOTAX study. J Clin Oncol 2008;26:5269-5274.

44. Trimble EL, Ungerleider RS, Abrams JA, et al. Neoadjuvant therapy in cancer treatment. Cancer 1993;72(11 Suppl):3515-3524.

45. Tam S, Du XL, Lewis CM, et al. The effect of facility volume on treatmen guideline compliance and overall survival in oral tongue squamous cell carcinoma [abstract]. J Clin Oncol 2018;36(Suppl):Abstract 17. 
46. Espinoza-Mercado F, Borgella JD, Berz D, et al. Disparities in compliance with national guidelines for the treatment of malignant pleural mesothelioma. Ann Thorac Surg 2019;108:889-896.

47. Birkmeyer JD, Warshaw AL, Finlayson SR, et al. Relationship between hospital volume and late survival after pancreaticoduodenectomy. Surgery 1999;126:178-183.

48. Chen AY, Fedewa S, Pavluck A, et al. Improved survival is associated with treatment at high-volume teaching facilities for patients with advanced stage laryngeal cancer. Cancer 2010;116:4744-4752.

49. Cheung MC, Hamilton $\mathrm{K}$, Sherman R, et al. Impact of teaching facility status and high-volume centers on outcomes for lung cancer resection: an examination of 13,469 surgical patients. Ann Surg Onco 2009;16:3-13.

50. Gutierrez JC, Perez EA, Moffat FL, et al. Should soft tissue sarcomas be treated at high-volume centers? An analysis of 4205 patients. Ann Surg 2007;245:952-958.

51. Kalbasi A, Swisher-McClure S, Mitra N, et al. Low rates of adjuvant radiation in patients with nonmetastatic prostate cancer with high-risk pathologic features. Cancer 2014;120:3089-3096.

52. Bilimoria KY, Bentrem DJ, Stewart AK, et al. Comparison of commission on cancer-approved and -nonapproved hospitals in the United States: implications for studies that use the National Cancer Data Base. J Clin Onco 2009;27:4177-4181.

\title{
VIRTUAL ONCOLOGY POLICY SUMMIT
}

\author{
Innovative Solutions to Drive \\ Down Healthcare Costs: \\ Implications for Access to \\ High Quality Cancer Care
}

\section{Wednesday, September 9, 2020 10:00 AM - 2:25 PM EDT}

\section{Free Online Program}

\section{Register: NCCN.org/policy}

Supported by Adaptive; ADC Therapeutics; AmerisourceBergen; Apobiologix; Astellas; AstraZeneca through its NCCN Corporate Council Membership; BeiGene, Ltd.; bluebird bio; Boehringer Ingelheim Pharmaceuticals, Inc.; Dendreon Pharmaceuticals; Eisai Inc; EMD Serono; Exelixis; Foundation Medicine, Inc.; Genentech; GSK; Heron; Incyte Corporation; Janssen Oncology; Pharmaceutical Companies of Johnson \& Johnson; Kite, a Gilead Company; Lilly; MorphoSys US, Inc.; Novartis; Regeneron Pharmaceuticals, Inc.; Sun Pharma Oncology; Takeda; and Verastem Oncology. Supported by an independent educational grant from Merck \& Co., Inc. This activity was made possible by Pharmacyclics, an AbbVie Company.

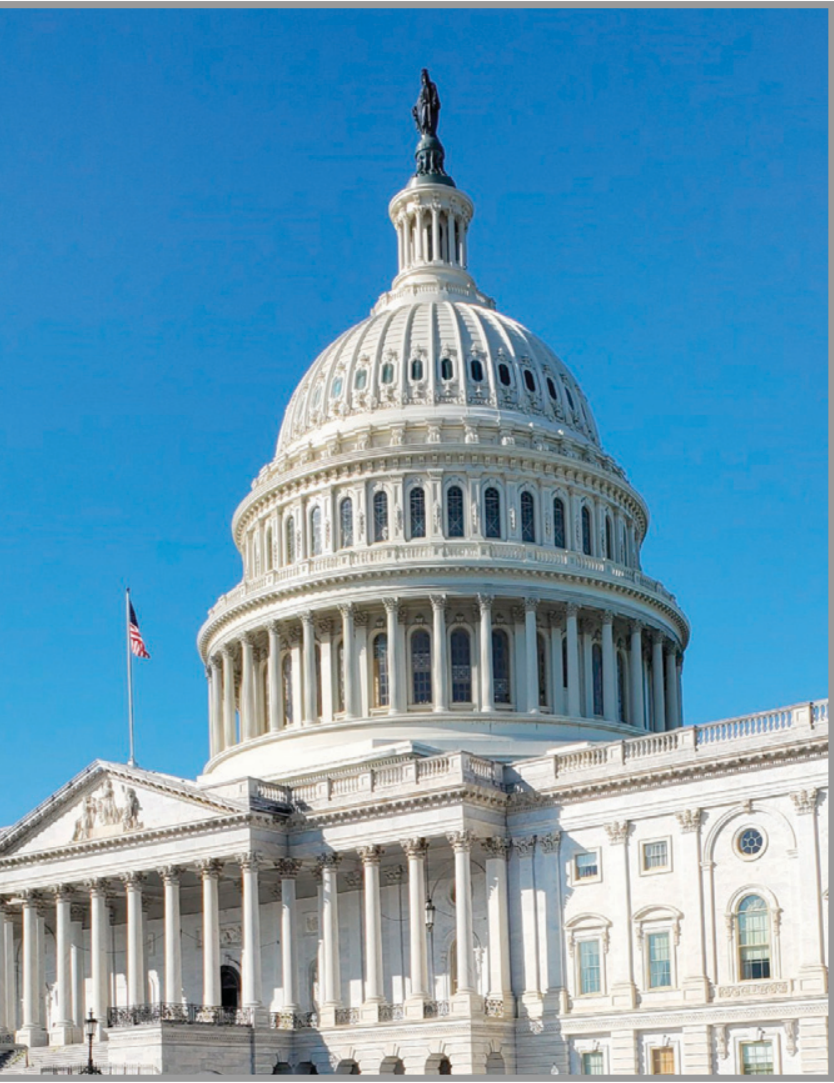


Supplemental online content for:

\section{Low Rates of Chemotherapy Use for Primary, High-Grade Soft Tissue Sarcoma: A National Cancer Database Analysis}

Danielle S. Graham, MD, MBA; Mykola Onyshchenko, MD; Mark A. Eckardt, MD; Benjamin J. DiPardo, MD; Sriram Venigalla, MD; Scott D. Nelson, MD; Bartosz Chmielowski, MD; Arun S. Singh, MD; Jacob E. Shabason, MD, MTR; Fritz C. Eilber, MD; and Anusha Kalbasi, MD

J Natl Compr Canc Netw 2020;18(8):1055-1065

eFigure 1: Analysis of Annual Sarcoma Surgical Case Volume eFigure 2: Distance From Patient Residence to Treatment Facility eFigure 3: Trends in Chemotherapy Use, Multiagent Chemotherapy Use, and Neoadjuvant Chemotherapy Use eTable 1: Study Cohort Characteristics eTable 2: Analysis of Temporal Trend of Chemotherapy Use 


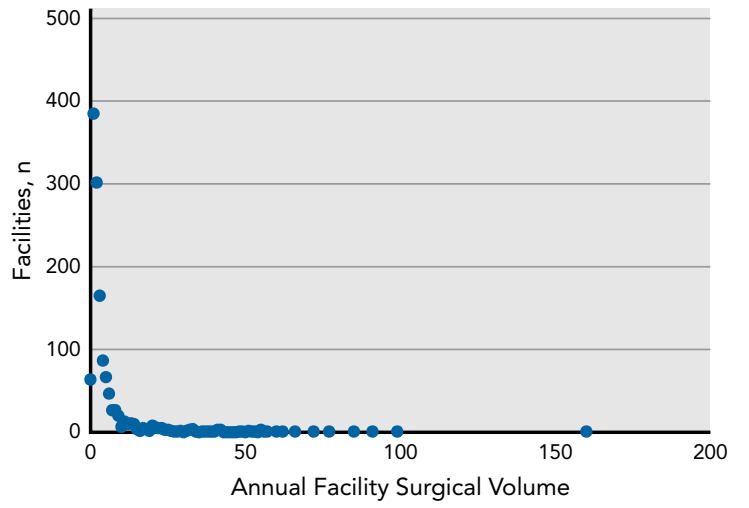

eFigure 1. Analysis of annual sarcoma surgical case volume (by facility) in the National Cancer Database (soft tissue sarcoma database, $n=106,822$ ) from 2004 to 2016 . Facilities in the 99th percentile performed $>55$ sarcoma surgeries per year. One facility performed 160 sarcoma surgeries per year, and the next-highest-volume facility performed 99 sarcoma surgeries per year. In the final study pop-

ulation, 19 centers $(4.9 \%)$ were categorized as high volume and 367 (95.1\%) were categorized as low volume. A total of 15,194 (76.1\%) patients were seen at low-volume centers, whereas 4,775 patients (23.9\%) were seen at high-volume centers.

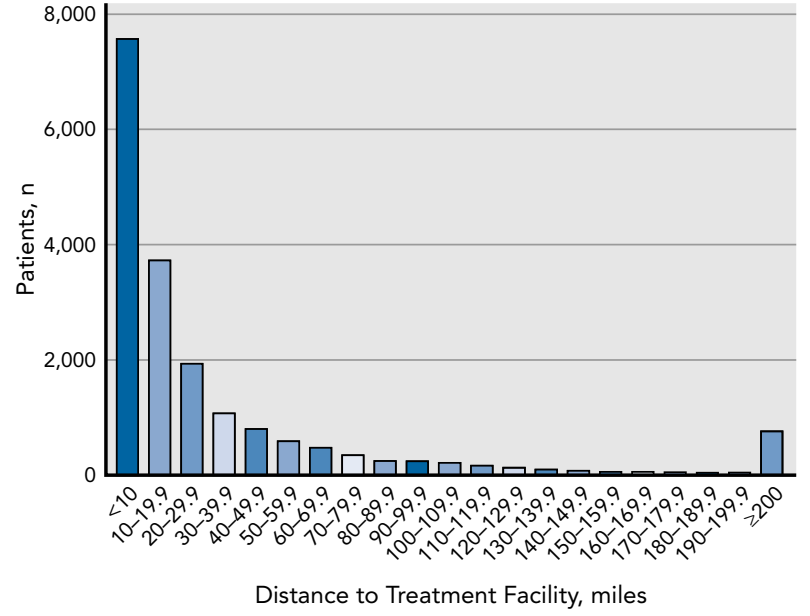

eFigure 2. Distance from patient residence to treatment facility for adult patients with primary high-grade soft tissue sarcoma in the National Cancer Database from 2004 to 2016. 
A

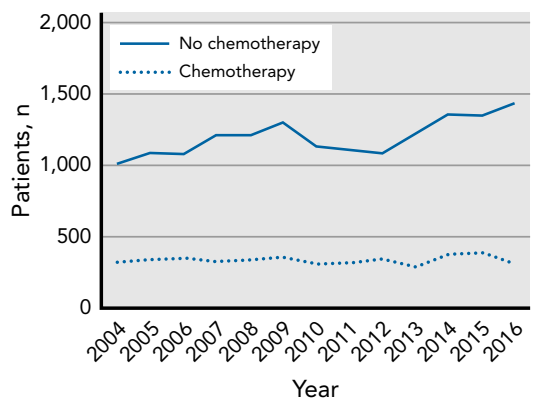

B

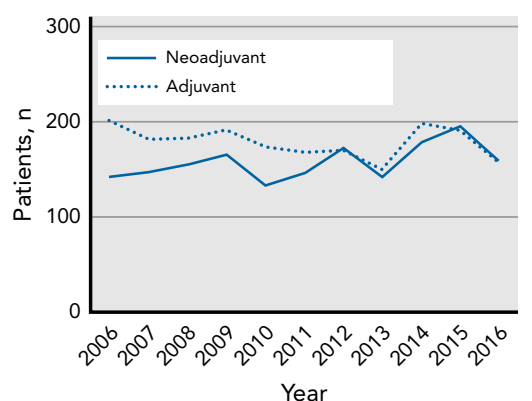

C

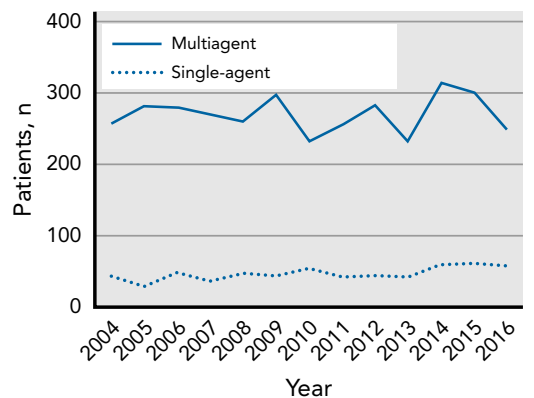

eFigure 3. Trends in (A) chemotherapy use, (B) multiagent chemotherapy use, and (C) neoadjuvant chemotherapy use in adult patients with primary high-grade soft tissue sarcoma in the National Cancer Database from 2004 to 2016. 


\section{eTable 1. Study Cohort Characteristics}

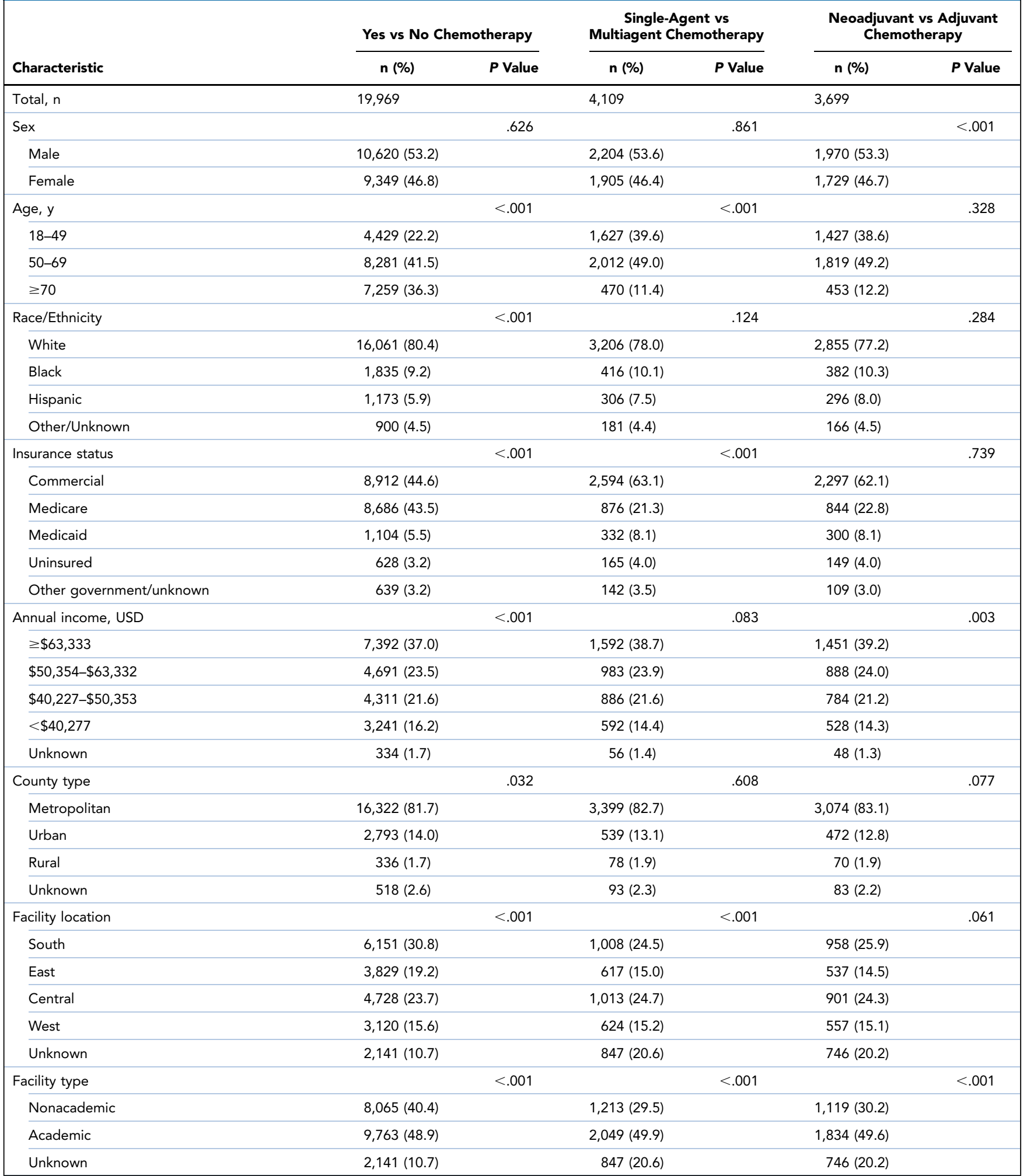




\section{eTable 1. Study Cohort Characteristics (cont.)}

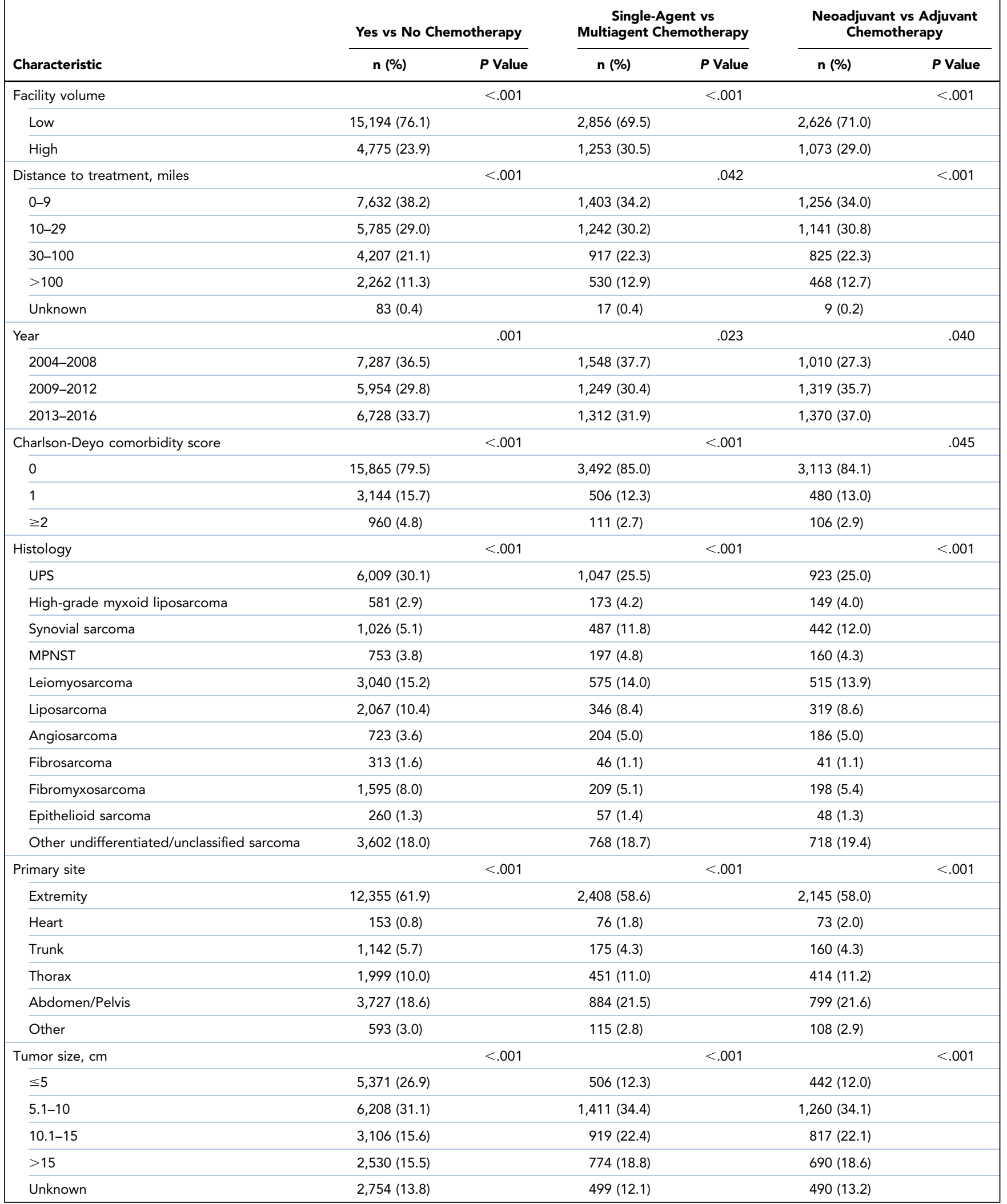




\section{eTable 1. Study Cohort Characteristics (cont.)}

\begin{tabular}{|c|c|c|c|c|c|c|}
\hline \multirow[b]{2}{*}{ Characteristic } & \multicolumn{2}{|c|}{ Yes vs No Chemotherapy } & \multicolumn{2}{|c|}{$\begin{array}{l}\text { Single-Agent vs } \\
\text { Multiagent Chemotherapy }\end{array}$} & \multicolumn{2}{|c|}{$\begin{array}{l}\text { Neoadjuvant vs Adjuvant } \\
\text { Chemotherapy }\end{array}$} \\
\hline & n (\%) & $P$ Value & n (\%) & $P$ Value & n (\%) & $P$ Value \\
\hline Depth & & $<.001$ & & .005 & & .134 \\
\hline Deep & $9,027(45.2)$ & & $2,274(55.3)$ & & $2,132(57.6)$ & \\
\hline Superficial & $4,908(24.6)$ & & $565(13.8)$ & & $529(14.3)$ & \\
\hline Unknown & $6,034(30.2)$ & & $1,270(30.9)$ & & $1,038(28.1)$ & \\
\hline Surgical margins & & $<.001$ & & $<.001$ & & $<.001$ \\
\hline Negative & 15,169 (76.0) & & $3,076(74.9)$ & & $2,748(74.3)$ & \\
\hline Positive & $3,525(17.6)$ & & $687(16.7)$ & & $639(17.3)$ & \\
\hline Unknown & $1,275(6.4)$ & & $346(8.4)$ & & $312(8.4)$ & \\
\hline Radiation therapy & & $<.001$ & & .002 & & $<.001$ \\
\hline Yes & $10,949(54.8)$ & & $2,468(60.1)$ & & 2,215 & \\
\hline No & $9,020(45.2)$ & & 1,641 (39.9) & & $1,484(40.1)$ & \\
\hline
\end{tabular}

Abbreviations: MPNST, malignant peripheral nerve sheath tumor; UPS, undifferentiated pleomorphic sarcoma. 


\section{eTable 2. Analysis of Temporal Trend of} Chemotherapy Use

Year OR $(95 \% \mathrm{Cl}) \quad P$ Value

Temporal trend of chemotherapy use 2004-2016

\begin{tabular}{lll}
\hline 2004 & Ref & \\
\hline 2005 & $0.98(0.83-1.17)$ & .858 \\
\hline 2006 & $1.01(0.85-1.20)$ & .902 \\
\hline 2007 & $0.86(0.72-1.02)$ & .087 \\
\hline 2008 & $0.88(0.74-1.04)$ & .142 \\
\hline 2009 & $0.86(0.73-1.03)$ & .098 \\
\hline 2010 & $0.86(0.72-1.02)$ & .086 \\
\hline 2011 & $0.89(0.75-1.06)$ & .198 \\
\hline 2012 & $1.00(0.84-1.20)$ & .960 \\
\hline 2013 & $0.75(0.63-0.90)$ & .002 \\
\hline 2014 & $0.87(0.74-1.04)$ & .120 \\
\hline 2015 & $0.90(0.76-1.07)$ & .245 \\
\hline 2016 & $0.69(0.58-0.83)$ & $<.001$ \\
\hline
\end{tabular}

Temporal trend of multiagent chemotherapy use 2004-2016

\begin{tabular}{lll}
\hline 2004 & Ref & \\
\hline 2005 & $1.68(1.01-2.78)$ & .044 \\
\hline 2006 & $0.97(0.62-1.52)$ & .902 \\
\hline 2007 & $1.25(0.78-2.01)$ & .356 \\
\hline 2008 & $0.93(0.59-1.45)$ & .735 \\
\hline 2009 & $1.16(0.73-1.82)$ & .533 \\
\hline 2010 & $0.72(0.46-1.11)$ & .140 \\
\hline 2011 & $0.99(0.63-1.57)$ & .973 \\
\hline 2012 & $1.10(0.70-1.73)$ & .689 \\
\hline 2013 & $0.90(0.57-1.42)$ & .648 \\
\hline 2014 & $0.90(0.59-1.38)$ & .640 \\
\hline 2015 & $0.82(0.54-1.26)$ & .368 \\
\hline 2016 & $0.73(0.47-1.13)$ & .155 \\
\hline
\end{tabular}

Temporal trend of neoadjuvant chemotherapy use 2006-2016

\begin{tabular}{llc}
\hline 2006 & Ref & \\
\hline 2007 & $1.14(0.84-1.55)$ & .390 \\
\hline 2008 & $1.20(0.89-1.62)$ & .241 \\
\hline 2009 & $1.22(0.91-1.65)$ & .188 \\
\hline 2010 & $1.08(0.79-1.48)$ & .620 \\
\hline 2011 & $1.23(0.90-1.68)$ & .189 \\
\hline 2012 & $1.43(1.06-1.94)$ & .020 \\
\hline 2013 & $1.34(0.98-1.83)$ & .068 \\
\hline 2014 & $1.27(0.95-1.71)$ & .110 \\
\hline 2015 & $1.45(1.08-1.94)$ & .014 \\
\hline 2016 & $1.43(1.05-1.95)$ & .022 \\
\hline
\end{tabular}

Abbreviation: OR, odds ratio. 